\title{
FALA E ESCRITA: CAMINHOS QUE SE CRUZAM NO ENSINO LINGUÍSTICO
}

\author{
Arabie Bezri Hermont \\ Ev'Angela Batista Rodrigues de Barros
}

RESUMO

Analisamos, à luz de abordagens que explicam o processo de aquisição da escrita e de consideraçôes sobre aspectos sociolinguísticos, desvios de grafias encontrados em cinquenta textos produzidos por alunos dos ciclos inicial e final do ensino fundamental, de escolas públicas da Grande $\mathrm{BH}$. Os resultados indicam distintas causas dos "erros" de ortografia e evidenciam maior frequência dos desvios provocados por interferências do dialeto dos aprendizes.

Palavras-chave: aprendizagem da escrita; ortografia; variações linguísticas.

\section{Um breve introito à discussão}

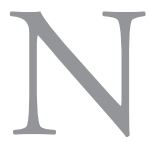

este artigo, pretendemos abordar as relaçōes estabelecidas entre fala e aprendizagem da escrita e as contribuiçóes que a Sociolinguística pode trazer para a compreensão de grafias desviantes em relação à norma padrão.

Espera-se que o ensino de língua materna na educação básica contribua para a aquisição de certas competências linguístico-discursivas dos aprendizes, sem deixar de lado o domínio da norma padrão. Nesse sentido, não é recente a explicitação, entre os objetivos do ensino de língua portuguesa (LP) na educação básica nos Parâmetros Curriculares Nacionais (PCN), de aspectos desejáveis à formação de qualquer cidadão brasileiro na contemporaneidade, como condição de cidadania: 
utilizar diferentes registros, inclusive os mais formais da variedade linguística valorizada socialmente, sabendo adequá-los às circunstâncias da situação comunicativa de que participam; conhecer e respeitar as diferentes variedades linguísticas do português falado; conhecer e analisar criticamente os usos da língua como veículo de valores e preconceitos de classe, credo, gênero ou etnia. (BRASIL, 1997, p. 33)

No entanto, ainda que se venha discutindo pelo menos nas últimas três décadas sobre a relevância da compreensão de como aspectos sociolinguísticos interferem na aprendizagem da escrita padrão, perdura ainda, na prática docente, a noção de "erros" em vez da constatação de "diferenças". Assim, dos três itens apresentados acima, parece-nos que somente o primeiro tem sido alvo de atenção pedagógica.

Sabe-se que a criança, em seu processo de aprendizado da escrita da língua portuguesa, testa e refaz hipóteses até chegar à fase em que coloca um símbolo para cada som pronunciado (escrita alfabética). Entretanto, ainda há um caminho a percorrer até ter um conhecimento estável da ortografia oficial. E é nesse contexto que o trabalho ora apresentado insere-se: trataremos a alfabetização em uma instância em que se verifique a influência do dialeto do alfabetizando no aprendizado da ortografia.

As análises apresentadas apoiam-se em vários autores que se dedicam a entender a relação entre fala e aprendizado da escrita e da ortografia, tais como Lemle (2004) e Oliveira (2006), e em autores que empreendem seus esforços na compreensão da relação linguagem e sociedade, como Bortoni-Ricardo (2004).

Para Oliveira (op.cit.), por exemplo, todo processo de aprendizado da escrita é intermediado pela oralidade. Vejamos a produção textual a seguir: 
Gravura 1. Influência da oralidade na escrita infantil

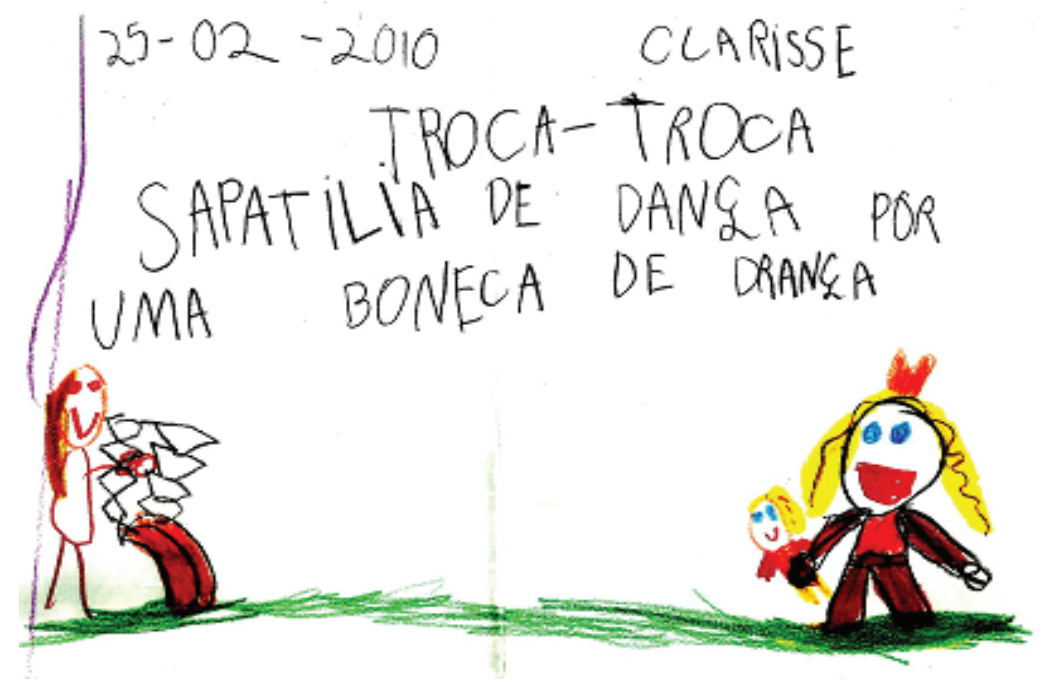

Fonte: dados pessoais das autoras.

No texto mencionado, a escrita de "sapatilia" deve-se à influência do dialeto da aprendiz. Em vez de falar o som lateral palatal $[\bullet]$, costumeiramente representado na ortografia pelo dígrafo "lh", a criança fala o som [li] e, por isso, escreve da forma como o fez.

Em Bortoni-Ricardo (2004), pode-se entender o processo de aprendizado da língua escrita como uma "transição do domínio do lar para o domínio da escola", ou seja, "uma transição de uma cultura predominantemente oral para uma cultura permeada pela escrita", à qual a autora chama de "cultura de letramento" (BORTONI-RICARDO, 2004, p. 24)

No texto a seguir, uma lista de compras feita por um caseiro (endereçada ao seu patrão, dono de um sítio), pode-se observar uma escrita calcada na forma como aquele fala. Assinale-se que o texto produzido por ele traz vários exemplos de escrita reproduzindo traços de uma fala estigmatizada: 
Gravura 2. Influência da oralidade sobre a escrita de adulto pouco escolarizado

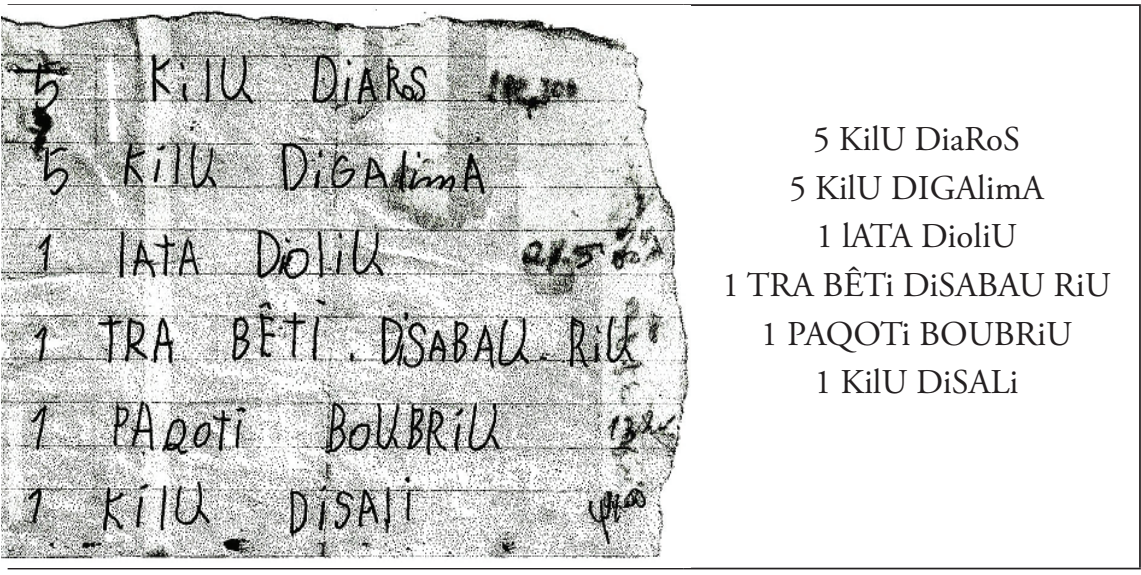

Fonte: dados pessoais das autoras.

A pessoa que a escreveu essa lista de compras, adulta e com pouca escolarização, o fez baseando-se na sua forma de falar: "kilu" (quilo), "diaros" (de arroz), "digalima” (de galinha), "dioliu” (de óleo), "disabau” (de sabão), "boubriu" (Bombril) e "paqoti" (pacote), "disali" (de sal). A análise dessas grafias evidencia o desconhecimento de algumas regras - de segmentação (diferença entre vocábulos fonológicos/morfológicos) ou de seleção do grafema, tais como o uso da letra "o" em sílaba átona final (em que, no dialeto mineiro, temos o som $[\mathrm{u}]$ ), o uso de "rr" em posição intervocálica, o uso dos dígrafos "nh" e "qu", a utilização do ditongo nasal "ão" (na palavra "sabão" e "om" na palavra "Bombril").

Todas essas grafias, aos olhos do mundo letrado, mas não especializado em linguística, levam a uma avaliação negativa. A pessoa é considerada analfabeta e, por isso, detentora de menor valia (aqui, o "capital linguístico" se relaciona também ao "capital socioeconômico" a ele atribuído). Quando se verifica a escrita de "disali", as pessoas tendem a rir mais, pois está claro que esta pessoa, além de escrever "errado", fala "errado", um português "caipira”. E note-se que esse fenômeno de acréscimo, chamado paragoge, é extremamente comum na constituição da Língua Portuguesa a partir do Latim e, ainda hoje, no aportuguesamento de palavras estrangeiras, como "lunch/lanche", "team/ 
time". Mas, no caso de "sali", há um valor pejorativo. O que não se percebe, porém, é que temos, dentro do sistema linguístico, explicações para todas as grafias feitas no bilhete. Ou seja, essa pessoa ou outra qualquer, nas mesmas condiçôes de letramento, poderia usar, talvez, um "c" ou "k" em "paqoti”, mas nunca escreveriam "paqoti" usando, no lugar do "q", um "l” ou "m".

Nessa perspectiva, levantamos algumas perguntas: as palavras com grafias desviantes do padrão podem ser explicadas pelo sistema linguístico? Quais são, de fato, grafias desviantes do padrão que se originam da influência dialetal e como podemos identificá-las? Por fim, as escritas que revelam influência do dialeto são todas estigmatizadas? É nosso objetivo desenvolver, neste artigo, uma abordagem que vise a dar resposta a tais perguntas.

Este artigo está organizado da seguinte forma: inicialmente, apresentamos abordagens que têm o objetivo de demonstrar quais são as relaçóes estabelecidas entre o sistema fonológico e a ortografia oficial do português. Depois, apresentaremos alguns pressupostos teóricos da sociolinguística, a fim de evidenciar possíveis contribuiçóes dessa área para uma melhor compreensão de grafias desviantes da norma padrão que podem surgir no processo de aquisição da escrita. Todo esse aporte teórico é trazido para que se proceda à análise de textos de crianças alfabetizandas e de alunos do nono ano. Em seguida, traremos nossas consideraçóes finais.

\section{Abordagens que visam a explicar as relações entre o sistema fonológico e a ortografia}

A partir da década de 1980, intensificaram-se, no cenário das instituiçóes destinadas à formação de professores de ensino básico e mesmo no interior das escolas de ensino fundamental, movimentos que evidenciam o esforço de se entender a melhor forma de ensinar o indivíduo a ler e a escrever. Inúmeros trabalhos demonstram que tal processo é influenciado pela fala e defendem que, dentro do processo de aquisição do sistema ortográfico, as crianças, inicialmente, baseiam-se em sua fala e somente em uma fase posterior é que passam a compreender a arbitrariedade da escrita em vários aspectos e assimilam os casos previstos por regras. Alguns aprendizes, porém, jamais chegam ao estágio ideal - de passarem, em suas escritas, a regular-se pelas regras da língua e não pelas da fala, que, por idiossincráticas, conduzem ao desvio em relação à forma convencional. 
Para Lemle (2004), no processo de aquisição da escrita, o aluno inicialmente traça uma relação direta entre letra e som, ou seja, pauta-se na própria fala achando que esta mantém estreito vínculo com a escrita. Nessa fase, a criança acredita que há um modelo harmonioso, em que o sistema alfabético consiste de uma relação biunívoca - para cada letra um som e, para cada som, uma letra. Mas essa relação ideal só acontece em poucos casos, a saber: a correspondência entre letras/fonemas: "p" e /p/; "b" e /b/; "f" e /f/; "v" e /v/; "t" e /t/; "d" e /d/; e "a" e /a/.

De acordo com Lemle, com o passar do tempo, as crianças terão cada vez mais contato com a escrita e com a leitura e acabarão descobrindo que nem todas as letras representam o mesmo som na hora de escrever. O aprendiz, gradativamente, passa a inferir que, "para cada som numa dada posição, há uma letra; a cada letra numa posição, corresponde um dado som" (LEMLE, 2004, p. 29). É o caso de "cachorro": escreve-se com "o" na sílaba final, mas, quando se pronuncia, tem som de "u". Isso ocorre em sílabas átonas finais. Outro equívoco que as crianças, nessa fase, podem cometer é a escrita de "eles cantão", no lugar de "eles cantam".

Interessante observar que os casos citados - o uso de "u" no lugar de "o" e o uso de "am" no lugar de "ão" - estâo relacionados à posição de sílabas átonas e tônicas. Ainda, estariam enquadrados nessa fase casos como a grafia de "tenpo", no lugar de "tempo". Nesse caso, o que está em jogo é uma regra que deve ser registrada: antes de "p" e "b", usa-se o "m" (devido à assimilação, já que são as três únicas consoantes bilabiais da língua portuguesa). Diante de outras consoantes (produzidas em diferentes pontos de articulação no interior da cavidade bucal), usa-se o "n". Enfim, também na segunda etapa, a criança encontra-se presa à ideia de que a escrita representa a fala.

A criança encontra-se na terceira etapa quando se depara com escritas não previstas por regras, de palavras cujas letras podem representar fones idênticos em contextos idênticos, tais como a letra " $x$ " que pode ter o som [ $\square$ ] como em "xingou", o som [z], como em "exato", o som [s], como em "máximo", o som [ks], como em "táxi”.

A quarta etapa, para Lemle, seria caracterizada pela percepçáo das regularidades ligadas à morfologia das palavras. Por exemplo, o sufixo “-eza” seria escrito com "z" e é um substantivo que contém o sentido de qualidade e advém de um adjetivo. $\mathrm{O}$ mesmo ocorreria com outros itens desse paradigma 
- moleza, certeza, pobreza, riqueza. De acordo com a autora, o alfabetizando deve ser conduzido no caminho do conhecimento das unidades menores da língua, que são os morfemas, o que facilitaria o acerto de outros casos de grafia (como o-ES(A), em adjetivos pátrios, o-SSE nos verbos no subjuntivo, etc.).

Dito tudo isso, podemos verificar que o que a autora denomina "segunda etapa da alfabetização" tem, como exemplos, palavras com características diferentes. O fato de uma criança escrever "tempo" com "m” ou " $n$ ”, apesar de sabermos de traços articulatórios que incentivam tal grafia (porque tanto o "m" quanto o "p" são bilabiais e o "n" é alveolar), para nós, não tem interferência do dialeto. Já a colocação de "u" em "mato" ou de "i" em "bode" nos parece uma questão que pode ser explicada pela tonicidade da sílaba, mas também, e principalmente, pela influência do dialeto do aprendiz na grafia da palavra.

Dessa forma, percebe-se que os desvios previstos como de segunda etapa englobam casos resultantes de influências dialetais. De forma muito interessante também, os exemplos dados pela autora como referentes à terceira etapa, compreendem aqueles em que os alfabetizandos devem guardar a forma gráfica na memória. Como exemplo, cita palavras como "gigante" e "craro". Com certeza, a explicação para a grafia de "gigante" (se com "g” ou com “j”) e para a grafia de "craro" (se com "l" ou com "u") é distinta. Para o último caso, consideramos que há uma forte tendência de a pessoa grafar incorretamente em função de traços característicos do seu dialeto.

Oliveira (2006) nos traz reflexôes acerca das relaçóes estabelecidas entre os aspectos ortográficos e o sistema fonológico do português. Postula que o aprendiz, durante o processo de aquisição da escrita, move-se de um sistema de representação pautado na fala para um sistema de representação amparado nas regras da língua. Uma vez em conflito com a hipótese inicial da correspondência som/letra, o aprendiz é levado a refletir sobre as especificidades de sua língua do ponto de vista ortográfico, a verificar que existem várias formas de se pronunciar uma palavra, mas apenas uma grafia socialmente legitimada.

Como se pode verificar, o fator "influência da oralidade na escrita", de certa forma, aproxima os trabalhos de Lemle (2004) e de Oliveira (2006), uma vez que ambos apontam, como forma de início da aprendizagem, a relação direta entre letra e som estabelecida pelo aprendiz, a relação de concorrência entre letras no momento de grafar-se uma palavra e a relação de arbitrariedade na escrita, sendo esta aprendida ao longo da vida por meio da memorização 
e da consulta ao dicionário. O que difere as duas propostas é que Oliveira (2006) faz uma classificação mais detalhada das grafias desviantes feitas por parte dos alunos em processo de aprendizagem de escrita.

Não abordaremos toda a categorização proposta pelo autor; focalizaremos apenas algumas explicaçóes para os denominados "erros", quais sejam: (a) violaçôes das regras invariantes que controlam a representação de alguns sons, em que entram os casos de escrita que se baseiam na pauta sonora e que, ao mesmo tempo, são regidos por regras. Uma grafia como "gera" no lugar de "guerra" estaria enquadrada nesta categoria. Ou seja, o aprendiz está violando uma escrita que deve sempre ser feita com o dígrafo "gu" (antes de -e) e do dígrafo -rr intervocálico; (b) violaçóes da relação entre os sons e os grafemas por interferência das características estruturais do dialeto do aprendiz. $\mathrm{O}$ aluno escreverá de acordo com seu dialeto e, como os dialetos do português não são idênticos, os problemas de escrita serão variados. Um mineiro que fala "bunitu", provavelmente, no início do processo da aprendizagem da escrita, escreverá "bunitu" em vez de "bonito"; (c) violaçâo das formas dicionarizadas, em que estariam problemas mais sérios a enfrentar, pois as grafias das palavras são de natureza totalmente arbitrária - "cesta-feira" ou "sexta-feira"? "Cinto" ou "sinto"? "Gelo" ou "jelo"?

Dessa maneira, verificamos que há escritas que são influenciadas pelo dialeto e que não devem ser categorizadas de forma similar à dos demais casos (desconhecimento de regras, hipercorreção, etc.). Colocar tipos distintos de grafias desviantes numa mesma categoria pode mascarar a compreensão das diferenças e, portanto, dificultar a intervenção do professor.

Nesse contexto, é também importante enfatizarmos que o aprendiz do sistema da escrita ancora-se em sua fala e o usuário da escrita, ao produzir um texto, apoia-se no conhecimento que já tem sobre o código da escrita de sua língua. Como forma de evidenciar isso, apresentamos uma experiência vivida por alunos adultos que se veem na necessidade de testarem hipóteses de escrita.

Em uma disciplina de Alfabetização e Letramento, no terceiro período do curso de Pedagogia, $2^{\circ}$ semestre de 2014, a fim de levar os alunos a refletirem sobre a construção da escrita, foi-lhes solicitada, por meio de um ditado, a escrita de quatro frases. Vejamos algumas das formas com que tentaram se desincumbir da tarefa: 
Quadro 1. Escritas em diferentes línguas

\begin{tabular}{|ll|ll|}
\hline $\mathbf{1})$ & Ich habe zwei Kinder. & $\mathbf{2})$ & Tengo dos hijos. \\
- & Ixi rabe itsvai kinder. & - & Tengo dos irros. \\
- & Ixy habe itis vai. & - & Tengo dos hiros. \\
- & Is Habe itis wai quinda. & - & Tengo dos ihos. \\
- & Ixi rabe it's vai quindar. & Tember dos riros. \\
- & $\begin{array}{l}\text { Ishi habby its vai kindhar. } \\
-\end{array}$ & - & \\
\hline Iche rabe it is vai kinder & I have two children. & & Eu tenho dois filhos. \\
- & Ai reve thu chimder. & $\mathbf{4})$ & \\
- & I hever two children. & & \\
- & Y have two children. & & \\
\hline- & I have tow children. & Yai he two children. &
\end{tabular}

Fonte: dados obtidos em sala de aula. Acervo das autoras.

À exceção da última frase (4), que todos escreveram adequadamente, a correção coletiva do ditado rendeu boa discussão sobre o que seria "escrever ortograficamente”, pois houve variadas notaçōes para aquilo que ouviram (e desconheciam), ou seja, a escrita foi mediada pela oralidade, no entanto, o código lhes escapava, visto que a primeira frase era em alemão; a segunda, em espanhol; a terceira, em inglês. De forma análoga, em determinado estágio de sua aprendizagem, o indivíduo vê na escrita uma língua estranha, estrangeira, cuja estrutura fonológica deve dominar, mas, para tanto, precisa compreender o Sistema de Escrita Alfabética de tal língua.

Curiosamente, nas propostas de grafia das frases conforme as escutaram, os alunos de Pedagogia misturaram códigos (como o uso de "Y" como vogal, em "Ixy", ou do dígrafo "sh", como em "Ishi", que, notadamente, não fazem parte da forma usual de registro (grafemas) do Português Brasileiro (PB); nota-se o uso do apóstrofo, em "it's”, claramente por influência da língua inglesa, vista em alguma fase da vida escolar precedente desses universitários. Por outro lado, houve o uso do dígrafo -rr, em "irros", ao lado de um -r ("hiros") e do -j (“ijos”) - sendo esta última forma de representação gráfica do fonema /R/ não pertencente ao sistema do $\mathrm{PB}$. Percebe-se, então, algum conhecimento do sistema do espanhol, ainda que mínimo; e, por fim, ressalta-se o "m" em "chimder", que desconsidera uma regra ortográfica válida no PB. Ao lado 
desses aspectos, nota-se o "rever"/ "hever", em que o -r final representa uma hipercorreção, se considerarmos o fenômeno de apagamento da consoante $-r$ final, especialmente no dialeto falado em Belo Horizonte.

O que tudo isso evidencia? Há, sim, uma busca do acerto por parte do aprendiz e, para isso, ele precisa estabelecer hipóteses, com base em aprendizagens prévias, numa variante por ele dominada. E ortografia não é algo que se aprende de uma vez por todas - bastando memorização de itens, por meio de treinamentos exaustivos - o que fica mais evidente num período de transição como o atual, de mudanças provocadas por um acordo ortográfico entre países lusófonos, em que adultos também se sentem inseguros, por vezes, ao redigir, diante de novas convenções gráficas, ainda não consolidadas.

Nesse contexto, consideramos que alguns apontamentos trazidos pela Sociolinguística podem auxiliar a compreensão de grafias desviantes decorrentes da influência dialetal cometidas pelos aprendizes. Passaremos, na próxima seção, a discorrer sobre tal.

\section{Pressupostos da sociolinguística como auxiliares na compreensão de alguns problemas da escrita}

Além do desafio inerente ao processo inicial da aprendizagem da escrita, o indivíduo ainda tem que aprender a lidar com a dualidade entre registro formal e informal. E isso é algo bastante complexo.

Nesse contexto, ter um conhecimento mais abrangente das contribuiçôes da Sociolinguística pode ajudar o docente a vislumbrar ferramentas para auxiliar o aprendiz, pode atenuar o impacto do "mito da dualidade", ao se evidenciar que há tanto gêneros orais quanto escritos com distintos níveis de formalidade e de informalidade e, ainda, de retirar o peso do fracasso escolar, muitas vezes colocado sobre o aprendiz e seu círculo familiar, ao mostrar que o nível linguístico trazido pelo indivíduo é ponto de partida para se alçarem voos no que tange à aprendizagem da língua materna.

Sabemos que a pronúncia e a escolha lexical são os aspectos em que mais se evidencia a heterogeneidade. No entanto, os estudos linguísticos têm mostrado que as variaçóes linguísticas se dáo em diferentes níveis, como no âmbito da fonologia, da morfologia, da sintaxe, do léxico, da pragmática, do discurso, dentre outros. 
No que diz respeito às variaçóes fonológicas, o som [t $\mathrm{t}]$ é comum na variedade dialetal mineira, antes do som [i], representado pelas letras "e" ou "i", como em "leite" ['leyt $\mathrm{j} i]$ ou Tiago [t $\left.\mathrm{f} \mathrm{i}^{‘} \mathrm{agU}\right]$. O "l", em final de sílaba, é pronunciado como semivogal em grande parte do país, mas, no Sul do Brasil, pode surgir como velarizado. Esse som também pode indicar faixa etária (pronúncia residual neste estágio sincrônico do português brasileiro, em certas regiốes). O "r" em final de sílaba pode ser pronunciado como retroflexo (interior de São Paulo) ou como velar (no Rio de Janeiro) ou como glotal (em Minas Gerais).

No âmbito da morfologia, nível da constituição das palavras, é tendência regularizar certos verbos irregulares, como "quando eu pôr" ou defectivos, como em "isso não se adéqua". Pode haver substituição de formas verbais: um exemplo é a "canibalizaçáo" dos tempos verbais do indicativo, que vêm se sobrepondo às formas do subjuntivo, tal como ocorre em "se eu podia, comprava mesmo", em vez de "pudesse/compraria", conforme uso prescrito na Gramática Tradicional. São, também, exemplos de variação no nível morfológico o uso do infinitivo em vez do imperativo, como em "Ler todo o material" e não "leia $(m)$ todo o material", e das escolhas lexicais (como "de modos que" para a expressão "de modo que").

No tocante à sintaxe, estudos sociolinguísticos nos mostram que a regra não redundante de concordância prevalece, tal como em "os menino", em que se marca apenas o determinante do $\mathrm{SN}$, independentemente da sua constituição, e tal raciocínio estende-se a sintagmas como "ques menino levado", forma corrente no interior de Minas Gerais, em que se vê o item "que" marcado para número. Outro fenômeno sintático é a substituição do relativo "cujo", como em "o pai que o filho foi expulso.." / "...o pai que o filho dele foi expulso...", em vez de "...o pai cujo filho foi expulso..". Os fenômenos ocorrentes nos dois exemplos em variação são denominados por Tarallo (1993) como "relativas cortadoras" ou "relativas copiadoras", respectivamente.

No âmbito pragmático-discursivo e do léxico, temos o uso de gírias e jargóes: como ocorre quando um jovem diz "marca aî" significando "dê um tempo", "aguarde"; ou utiliza a expressão "tô boladão", indicando que esteja irritado, nervoso.

Embora não se respalde em nenhum critério científico de avaliação das variantes dialetais, uma série de traços linguísticos fonológicos, morfológicos e sintáticos passa a ser considerada feia ou ridícula, o que acaba por transferir 
a seus enunciadores esses mesmos rótulos. Nesse sentido, Gnerre afirma que "uma variedade linguística 'vale' o que 'valem' na sociedade os seus falantes, isto é, como reflexo do poder e da autoridade que eles têm nas relaçóes econômicas e sociais." (GNERRE, 2001, p. 6-7).

Dentro desse contexto, podemos refletir sobre o papel da escola diante da situação sociolinguística do Brasil. Nota-se que a dificuldade da escola, contemporaneamente, de lidar com a questão da variedade linguística reside no fato de que, a partir da segunda metade do século XX, grande parte de uma população até então alijada da oportunidade de escolarização acedeu, gradualmente, aos bancos escolares. Nesse mesmo século, registra-se também um grande movimento migratório - de nordestinos para centros de influência urbana, megalópoles como São Paulo e Rio de Janeiro; de pessoas do interior dos estados para as capitais, em busca de melhor situação socioeconômica - por exemplo, de regióes pobres do Norte de Minas Gerais para Belo Horizonte. Junto com seu modo "esquisito" de falar, essas pessoas trouxeram uma cultura diferente, uma visão de mundo divergente da valorizada e tida como a ideal. Entre esses valores culturais e simbólicos que identificam uma comunidade está a língua, posto que é veículo de (auto)expressão e de transmissão/ manutenção de crenças, valores, ideologias, etc.

Bortoni-Ricardo (2004) afirma que não há divisões estanques entre os modos de falar, mas imbricamentos, que se dão devido a vários fatores e que constituem contínuos. Considerando-se os extremos desses três contínuos, teríamos experiências de oralidade ou de letramento; de procedência (rural/urbano); de monitoraçáo (maior ou menor, conforme requerido pelo contexto). Ocorre que, muitas vezes, as pessoas dominam certas situaçóes de oralidade (com maior ou menor grau de monitoração, mas não todas); dominam certas circunstâncias típicas de uma situação de letramento elevado, mas náo todos os aspectos desse âmbito; saíram de uma regiâo rural, mas não conseguiram adaptar-se plenamente a um contexto de urbanização - e ficam "no meio do caminho", como falantes "rurbanos", que oscilam em seus comportamentos linguísticos, ora apresentando formas próximas do padrão, ora formas completamente divergentes, destoantes e, por isso mesmo, recebem uma avaliação negativa.

A aprendizagem vivencial e concreta de língua com que as crianças acorrem às escolas, sobretudo às públicas, provoca, frequentemente, um grave conflito decorrente do confronto de saberes, pois a forma de língua apresentada 
pela maioria dos aprendizes difere exponencialmente daquela que devem ter como alvo, desejada pela escola, cheia de prescriçôes e idealizaçôes.

Nesse impasse, em que se busca uma produção textual grafada em consonância com os parâmetros normatizadores, os professores, por vezes, se esquecem de que a aprendizagem da escrita é um processo muito amplo, no qual, conforme Bunzen (2006), ao produzir um texto, "o aluno assume o papel de locutor, o que implica em: ter o que dizer; ter razóes para dizer o que tem a dizer; ter para quem dizer o que tem a dizer; assumir-se como sujeito que diz o que diz para quem diz; e escolher estratégias para dizer." (BUNZEN, 2006, p. 149).

Nessa perspectiva, a ortografia - aqui considerada em suas duas dimensóes, a lexical (troca de letras) e a gramatical (erros de concordância verbal) -, que, inicialmente, seria um aspecto menos relevante da textualização do que a coerência, por exemplo, acaba se tornando a principal causa de críticas e desqualificação do trabalho de produção textual, desconsiderando-se o conteúdo que o aprendiz desejou apresentar (e às vezes, o conseguiu; porém, o olhar do professor sobre os erros em detrimento dos acertos, a busca de uma higienização do texto, com base num parâmetro de "escrita correta", pode inverter o valor das condiçóes de textualidade). Assim, a quantidade de marcaçóes de erros gráficos gera um sentimento de baixa autoestima que em nada contribui para a melhoria da escrita do aluno da escola básica.

A seguir, procederemos à exposição da análise de textos produzidos por alunos de ensino fundamental com o objetivo de verificarmos quais são as grafias desviantes do padrão e, dentre essas, quais são derivadas de influência dialetal.

\section{Análises de desvios de grafias por parte de alunos alfabetizandos e de alunos do nono ano}

Nesta seção, apresentamos uma análise de alguns desvios de grafia verificados em textos produzidos por crianças em fase de alfabetização e por adolescentes cursando o último ano do ensino fundamental II. As crianças têm idade entre seis e sete anos e frequentam uma escola municipal em um bairro de classe média alta de Belo Horizonte (MG). Já os adolescentes têm idade entre 14 e 17 anos e frequentam uma escola municipal de Contagem (Grande $\mathrm{BH}$ ), situada em regiấo socialmente vulnerável e que atende a um público de estrato socioeconômico mais baixo. 
A ideia foi tecer uma comparação entre as produçóes de alunos iniciantes e concluintes do ensino fundamental, com intuito de verificar, quanto à ortografia, o que se consolidou (ou não) em termos de aprendizagem da escrita. Conforme preceituado pelas teorias trazidas à nossa discussão, a expectativa era de encontrar, nos corpora dos alunos do nono ano, maior observância das regras da língua, ou seja, menor submissão à influência da oralidade.

Constatamos que tanto as crianças que estão iniciando o fundamental I quanto os adolescentes que estão finalizando o fundamental II apresentam desvios de grafias em seus textos cuja explicação respalda-se no desconhecimento de aspectos do sistema linguístico e que há diferenças entre tais desvios: alguns são devidos à influência do dialeto do aprendiz, enquanto outros não o são.

Os textos solicitados às crianças tiveram como tema "O que quero ser quando crescer", já os textos produzidos pelos adolescentes tiveram como mote as eleiçóes presidenciais de 2014, em que os candidatos Dilma Rousseff e Aécio Neves disputavam o cargo no segundo turno. Vale dizer que os textos produzidos pelos alunos adolescentes foram mais extensos que os das crianças, como era de se esperar.

As grafias desviantes da ortografia padrão foram agrupadas de acordo com a natureza da escrita ${ }^{1}$.

Vejamos os resultados para omissóes de letras, nos textos analisados:

Quadro 2. Omissóes e inserçôes de letras e sílabas e palavras inexistentes

\begin{tabular}{|c|c|}
\hline $\begin{array}{c}\text { Textos das crianças no início do } \\
\text { Fundamental I }\end{array}$ & $\begin{array}{c}\text { Textos dos adolescentes no final do } \\
\text { Fundamental II }\end{array}$ \\
\hline $22,3 \%$ & $8,6 \%$ \\
\hline
\end{tabular}

Fonte: dados da pesquisa.

Como se pode depreender, as crianças apresentaram escritas de palavras ora faltando letras ou sílabas ("Profssora" para professora e "facidade" para facilidade), ora inserindo letras (munito" e "muto" para muito), ora escrevendo

1 Poucos foram os desvios observados nas grafias tanto das crianças quanto dos adolescentes em que se observava confusão em relação ao formato da letra e em relação aos desvios de grafias derivadas da dificuldade de fazer-se distinção entre sons surdos e sonoros e suas respectivas letras. Por isso, não vamos nos preocupar, aqui, em analisá-los. 
palavras não existentes em nossa língua (“cenbresoen" e "metediarar") - em $22,3 \%$ das vezes. Já os adolescentes demonstraram, em seus textos, grafias sem a consoante nasal em final de sílabas ("abições” para ambiçôes), sem o "r" em final de sílaba interna à palavra ("sevem" para servem) e palavras sem letras ou sílabas ("edução" para educação) - 8,6\% das vezes em que houve escrita desviante da padrão. Pudemos constatar que as crianças escrevem palavras faltando letras ou sílabas mais frequentemente que adolescentes de 14 a 17 anos. Como esse tipo de escrita é mais comum no início do processo de alfabetização, acreditamos que o resultado, apesar de não ser satisfatório (pois seria mais interessante que adolescentes não escrevessem palavras da forma relatada), é coerente.

Há determinadas regras da ortografia que, uma vez aprendidas, nunca mais serão esquecidas. Abaixo, veremos a porcentagem de desvios de grafias relacionados a tais regras.

Quadro 3. Desvios na escrita de palavras que são guiadas por regras que não variam

\begin{tabular}{|c|c|}
\hline $\begin{array}{c}\text { Textos das crianças no início do } \\
\text { Fundamental I }\end{array}$ & $\begin{array}{c}\text { Textos dos adolescentes no final do } \\
\text { Fundamental II }\end{array}$ \\
\hline $4,9 \%$ & $9 \%$ \\
\hline
\end{tabular}

Fonte: dados da pesquisa.

Nesse caso, os desvios estáo ligados ao uso das letras "m" antes de "p" e "b"; ao uso de "-ão" em sílaba tônica e de "-am” em sílabas átonas; ao uso de "-rr" em posiçấo intervocálica; ao uso do "q" sempre seguido de "u”. As crianças, em seus textos, demonstraram desvios de grafias em que não se observou o uso correto de tais regras em $4,9 \%$ das vezes. Nos textos dos adolescentes, para o mesmo caso, houve $9 \%$ de escritas desviantes. Como exemplo, podemos citar algumas grafias das crianças: "qero" (para quero) e "cachoros" (para cachorros). Dos textos dos adolescentes, podemos destacar: "seram" (para serão), "falāo" (para falam), "desenpenho" (para desempenho).

Vejamos agora o resultado para os desvios na grafia de palavras em que não se depende de qualquer regra, pois há arbitrariedade na sua escrita: 
Quadro 4. Desvios na escrita de palavras que NÃO são guiadas por regras

\begin{tabular}{|c|c|}
\hline $\begin{array}{c}\text { Textos das crianças no início do } \\
\text { Fundamental I }\end{array}$ & $\begin{array}{c}\text { Textos dos adolescentes no final do } \\
\text { Fundamental II }\end{array}$ \\
\hline $21,4 \%$ & $38,5 \%$ \\
\hline
\end{tabular}

Fonte: dados da pesquisa.

Nesse quadro, verificamos problemas para 21,4\% das grafias com "erro" nos textos das crianças e 38,5\% nos textos dos adolescentes. Exemplos retirados dos textos das crianças são: "crecer" (para crescer), "asim” (para assim), "paço" (para passo). Dos textos dos adolescentes, temos os seguintes exemplos: "auguns" (para alguns), "bouços" (para bolsos), "escluídos” (para excluídos), "cressa” (para cresça), "pença-se" (para pensa-se), "geito” (para jeito). Uma porcentagem maior de desvios de grafia para essa categoria é compreensível, dado o fato que deve haver memorização de cada palavra. Por outro lado, o fato de os adolescentes terem cometido mais desvios (inclusive em palavras corriqueiras, como "jeito" e "pensar"), após um período mais extenso de contato com a escrita escolar, significa que o ensino de ortografia tem sido ineficaz.

Nos textos analisados, verificamos que a segmentação das palavras nem sempre se dá de acordo com a norma padrão, conforme se pode depreender de:

Quadro 5. Equívocos na segmentação de palavras

\begin{tabular}{|c|c|}
\hline $\begin{array}{c}\text { Textos das crianças no início do } \\
\text { Fundamental I }\end{array}$ & $\begin{array}{c}\text { Textos dos adolescentes no final do } \\
\text { Fundamental II }\end{array}$ \\
\hline $5,8 \%$ & $2,9 \%$ \\
\hline
\end{tabular}

Fonte: dados da pesquisa.

As crianças, em fase inicial de aprendizagem da escrita, muito costumeiramente, ora juntam palavras distintas ("vose" para vou ser), ora segmentam palavras ("tan bem” para também). Tal equívoco ocorreu em 5,8\% nos textos das crianças. Já nos textos dos adolescentes, houve 2,9\% de equívocos dessa natureza, tais como "poriso" (para por isso) e "a queles" (para aqueles). 
Muitas vezes, o aluno grafa incorretamente uma determinada palavra, entretanto, o equívoco demonstra uma reflexão acerca de uma determinada regra da escrita. Por exemplo, na escrita de "vol" (para vou), a criança já refletiu que o som de "u" é grafado com "u", mas em outros momentos é grafado com "l”. Então, ele faz a opção pela segunda grafia. Ou seja, nesse momento, o aprendiz não está calcado na sua fala e, sim, em alguma regra da ortografia que já conhece. Nesses casos, o desvio na grafia é denominado hipercorreção. Vejamos o quadro em que constam escritas não padrão que foram decorrentes de hipercorreção:

Quadro 6. Casos de hipercorreção

\begin{tabular}{|c|c|}
\hline $\begin{array}{c}\text { Textos das crianças no início do } \\
\text { Fundamental I }\end{array}$ & $\begin{array}{c}\text { Textos dos adolescentes no final do } \\
\text { Fundamental II }\end{array}$ \\
\hline $8,7 \%$ & $25,3 \%$ \\
\hline
\end{tabular}

Fonte: dados da pesquisa.

Nos textos das crianças, verificamos $8,7 \%$ de equívocos em função de uma hipercorreção: hiscritor" (para escritor) - aqui uma clara tentativa de aproximação da palavra "escritor" com seu objeto de trabalho "história", além de "decedi" (para decidir) e "coidar" (para cuidar). Já nos textos dos adolescentes, verificamos muitos erros decorrentes de hipercorreção: 25,3\% - "rolbado" (para roubado), "repulblica” (para república), "opniāo” (para opinião), "desputa” (para disputa).

Por fim, apresentamos desvios de grafias decorrentes da influência direta do dialeto da criança e do adolescente. Verificamos 34\% de grafias dessa natureza nos textos das crianças e 38,5\%, nos textos dos adolescentes, conforme o quadro a seguir:

Quadro 7. Desvios na escrita de palavras guiados por influência do dialeto

\begin{tabular}{|c|c|}
\hline $\begin{array}{c}\text { Textos das crianças no início do } \\
\text { Fundamental I }\end{array}$ & $\begin{array}{c}\text { Textos dos adolescentes no final do } \\
\text { Fundamental II }\end{array}$ \\
\hline $34 \%$ & $38,5 \%$ \\
\hline
\end{tabular}

Fonte: dados da pesquisa. 
Podemos destacar, dos textos das crianças, os seguintes exemplos: "istuda" (para estudar), "comu” (para como), “jogado" (para jogador). Vemos, nesses exemplos, claros efeitos da forma como o indivíduo fala e transcreve para o seu texto. Ele usa o som [i], então, escreve com a letra "i” em "istuda”. Ele fala [u] e, portanto, escreve "u" na palavra "comu". No dialeto mineiro, também é comum a omissão do "r" em posição final de palavra. Daí as escritas do infinitivo "estudar" e do substantivo "jogador" sem o " $r$ " final. Temos, ainda nos textos das crianças, escritas como "fazedero" (para fazendeiro) e "bombero" (para bombeiro). No dialeto mineiro, o processo de monotongação (passagem de ditongo a uma só vogal) ocorre com frequência com o ditongo "ei" diante do tepe (o erre fraco).

Ainda retirado de textos das crianças, temos "dibrar" (para driblar). Nessa grafia, temos a revelação de dois fenômenos fonológicos muito comuns. Um é o rotacismo, mudança fonética que consiste na substituição de um som, e o outro é a síncope, que é a supressão de som no meio da palavra. O rotacismo ocorre na substituição do "l" por "r" e a síncope ocorre no apagamento do "r" da sílaba inicial. A criança assim fala, assim escreve.

Por fim, temos outro exemplo de interferência dialetal na escrita das crianças. Nesse caso, o exemplo revela questóes relacionadas à concordância: "as pessoa qi esta doente" (para "as pessoas que estão doentes").

Nos textos dos adolescentes, observamos vários problemas semelhantes aos que as crianças apresentaram, tais como "vota" (para votar), "melho" (para melhor), "robo" (para roubo), "governado" (para governador). Aliam-se a eles outros. Houve um grande número de escritas equivocadas para a conjunção "mas", em que foi utilizada a grafia "mais", claramente um reflexo do dialeto dos alunos. Observamos também uma grande quantidade de concordâncias verbais e nominais destoantes da oficial, tais como em "os cidadão escolhe um governado" (para "os cidadãos escolhem um governador"). Consideramos interessantes os seguintes exemplos de concordância ideológica: "muito politico corrupto prometem" (para "muitos políticos corruptos prometem"), em que o verbo parece concordar com a noção semântica inerente à palavra "muito". Raciocínio similar podemos fazer para o exemplo "político que fazem" (para "políticos que fazem"), em que consideramos a palavra "político" usada de forma genérica e, portanto, que reúne toda a classe de políticos.

Nos dois corpora, ou seja, nos textos das crianças e dos adolescentes, observamos que as maiores porcentagens de desvios de grafias devem-se à influência 
do dialeto do aprendiz. Ficam patentes, a nosso ver, que (a) a oralidade influencia a escrita dos estudantes ao longo de todo o ensino fundamental; (b) a escola tem sido ineficiente na condução do ensino da ortografia de modo a consolidar a passagem do "domínio do lar para o domínio da escola" (cf. Bortoni-Ricardo, op. cit.); (c) o desconhecimento de aspectos referentes à contextualização sociolinguística dos alunos faz com que não haja intervençôes específicas, a partir de um diagnóstico, que atendam às dificuldades manifestadas por aquele grupo de discentes e levem à superação destas.

\section{Considerações finais}

Neste artigo, apresentamos um arcabouço teórico que teve o objetivo de demonstrar algumas abordagens que visam a explicar as escritas desviantes, feitas por alunos, daquela prescrita pela ortografia oficial da Língua Portuguesa. Com base nesse aporte teórico, realizamos análises de cinquenta textos produzidos por alunos da fase inicial e final do ensino fundamental de escolas da Grande BH.

Todo esse percurso foi realizado a fim de respondermos às questóes levantadas no início deste trabalho: (a) as palavras com grafias desviantes do padrão podem ser explicadas pelo sistema linguístico? (b) Quais são, de fato, grafias desviantes do padrão que se originam da influência dialetal e como podemos identificá-las? (c) Por fim, as escritas que revelam influência do dialeto são todas estigmatizadas?

Como resposta à primeira pergunta, vimos que há explicaçóes para cada escrita desviante daquela prevista pela ortografia da língua portuguesa. Tanto que diversos autores já propuseram várias taxonomias, a fim de organizar, em categorias, as escritas desviantes feitas pelos aprendizes.

Em resposta à segunda pergunta, vimos que há vários tipos de grafias refletindo o dialeto do aprendiz. Tais escritas podem refletir aspectos da oralidade interferentes nos níveis fonológicos, morfológicos, lexicais, sintáticos, etc.

Por fim, em relação à terceira pergunta, pudemos verificar que há escritas desviantes do padrão menos estigmatizadas que outras e que isso se dá principalmente em função de quem a escreve. "Erros" previstos pelo sistema, cometidos por crianças em fase inicial de alfabetização, são mais admissíveis que os mesmos equívocos produzidos por estudantes que estão saindo do en- 
sino fundamental. Podemos, então, agregar a essa última questão a seguinte: o que a escola pode fazer em casos como esses? Para que a escola possa cumprir o papel que dela se espera, é imprescindível que os docentes enfrentem tal questão, saibam identificar os fenômenos linguísticos que se fazem presentes na sua sala de aula e que reconheçam e compreendam o perfil sociolinguístico de seus alunos para que possam, de forma respeitosa em relação aos saberes linguísticos desse grupo de alunos, possibilitar-lhes um aprendizado, no caso, da ortografia, de forma eficaz.

\section{Referências}

BORTONI-RICARDO, Stella Maris. Educação em lingua materna: a sociolinguistica em sala de aula. São Paulo: Parábola, 2004.

BUNZEN, Clecio. Da era da composição à era dos gêneros: o ensino de produção de texto no ensino médio. In: BUNZEN, Clecio; MENDONÇA, Márcia (Orgs.). Português no ensino médio e formação do professor. São Paulo: Parábola, 2006.

GNERRE, Maurizio. Linguagem, Escrita e Poder. São Paulo: Martins Fontes, 1991.

LEMLE, M. Guia teórico do alfabetizador. 16a ed. São Paulo: Ática, 2004.

OLIVEIRA, M. A. Conhecimento linguístico e apropriação do sistema de escrita. Belo Horizonte: CEALE, 2006. Ms.

TARALLO, Fernando. Diagnosticando uma gramática brasileira: O português d'aquém e d'além-mar ao final do século XIX. In. ROBERTS, I.; KATO, M. (Orgs.). Português brasileiro: uma viagem diacrônica. Homenagem a Fernando Tarallo. Campinas: Unicamp, 1993. 


\title{
SPEAKING AND WRITING: PATHS THAT CROSS IN TEACHING PORTUGUESE
}

\begin{abstract}
In the light of writing acquisition theories and remarks on sociolinguistic aspects, this work analyzes writing deviations found in 50 texts written by students in the early stages of literacy development and in the last year of Junior High School in Belo Horizonte Metropolitan Region. The results point out different causes for misspellings and highlight the interferences of learners' dialects as the greatest cause of deviations occurrence.
\end{abstract}

KEY WORDS: writing learning; spelling; language variations.

Recebido em: 31/03/2015

Aprovado em: 26/09/2015 